\title{
Memory and Metamemory: A Study of the Feeling-of-Knowing Phenomenon in Amnesic Patients
}

\author{
Arthur P. Shimamura and Larry R. Squire \\ Veterans Administration Medical Center, San Diego and Department of Psychiatry, University \\ of California, San Diego, School of Medicine
}

\begin{abstract}
Accuracy of the feeling of knowing was tested in patients with Korsakoff's syndrome, patients prescribed electroconvulsive therapy, four other cases of amnesia, and control subjects. In Experiment 1, we tested feeling-of-knowing accuracy for the answers to general information questions that could not be recalled. Subjects were asked to rank nonrecalled questions in terms of how likely they thought they would be able to recognize the answers and were then given a recognition test for these items. Only patients with Korsakoff's syndrome were impaired in making feeling-of-knowing predictions. The other amnesic patients were as accurate as control subjects in their feeling-of-knowing predictions. In Experiment 2, we replicated these findings in a sentence memory paradigm that tested newly learned information. The results showed that impaired metamemory is not an obligatory feature of amnesia, because amnesia can occur without detectable metamemory deficits. The impaired metamemory exhibited by patients with Korsakoff's syndrome reflects a cognitive impairment that is not typically observed in other forms of amnesia.
\end{abstract}

Often one experiences a sense or feeling of knowing some information without being able to recall it. In its most frustrating form the information seems to be on the "tip of the tongue." These experiences illustrate that we have knowledge about what we know, even when complete recall is not possible. Knowledge about one's memory capabilities and knowledge about strategies that can aid memory are termed metamemory (Brown, 1978; Flavell \& Wellman, 1977; Gruneberg, 1983). One manifestation of metamemory is the feeling-of-knowing phenomenon-the ability to judge the probability of future success in a memory test. Here we investigated the accuracy of the feelingof-knowing experience in amnesic patients.

The study of amnesia could help in explaining the relation between metamemory and memory. Amnesic patients exhibit severe impairments on tests of recall and recognition-they have deficits in the ability to store, organize, and consciously recollect events that occurred since the onset of amnesia (for reviews, see Cermak, 1982; Hirst, 1982; Squire \& Cohen, 1984; Weiskrantz, 1982). Yet in spite of this impairment in new learning capacity (i.e., anterograde amnesia), amnesic patients can learn and retain perceptual-motor and cognitive skills, often in normal fashion (Cohen, 1984; Cohen \& Squire, 1980; Corkin, 1968; Milner, 1962); and they can demonstrate normal priming

This research was supported by National Research Service Award MH08992 from the National Institute of Mental Health to Arthur Shimamura, the Medical Research Service of the Veterans Administration, and National Institute of Mental Health Grant MH24600 to Larry Squire. We thank Joyce Zouzounis, Kim Rivero-Frink, and Deborah Rosenthal for research assistance and Henry Roediger III, Thomas Nelson, and Elizabeth Glisky for helpful comments on earlier drafts.

Correspondence concerning this article should be addressed to Arthur P. Shimamura, Department of Psychiatry (V116), Veterans Administration Medical Center, 3350 La Jolla Village Drive, San Diego, California 92161. effects (Diamond \& Rozin, 1984; Graf, Squire, \& Mandler, 1984; Jacoby \& Witherspoon, 1982; Shimamura \& Squire, 1984; Squire, Shimamura, \& Graf, 1985; for review, see Shimamura, in press).

One possibility is that deficits in metamemory contribute to or cause amnesia. That is, lack of conscious knowledge about what is stored in memory and a lack of awareness about strategies to aid memory could contribute to poor performance on memory tests. By this view, amnesic patients should have difficulty in tasks that assess metamemory just as they have difficulty on conventional memory tests. Alternatively, the processes and brain systems that contribute to metamemory may be independent of the processes and brain systems required to establish memory itself. By this view, metamemory could be unaffected in amnesia and metamemory abilities may be present whenever amnesic patients perform above chance on a conventional memory test. Finally, it may be that only some forms of amnesia affect metamemory, whereas other forms of amnesia produce a selective deficit of memory, leaving metamemory abilities intact.

Hirst (1982) suggested that metamemory may be impaired in patients with Korsakoff's syndrome. Korsakoff's syndrome, the best studied form of amnesia, occurs as a result of chronic alcohol abuse and nutritional deficiency and is marked by severe anterograde amnesia as well as extensive loss of memory for remote events (Butters \& Cermak, 1980; Talland, 1965). These deficits occur in spite of intact immediate memory, IQ scores, and language functions. Hirst and Volpe (as cited by Hirst, 1982) interviewed amnesic patients and concluded that patients with Korsakoff's syndrome exhibited poorer knowledge of mnemonic strategies than patients with other etiologies of amnesia. In another study, patients with Korsakoff's syndrome were poorer than control subjects at predicting their performance on a free-recall test (Bauer, Kyaw, \& Kilbey, 1984). Other kinds of amnesic patients were not tested. 
Other observations have suggested that some impairments exhibited by patients with Korsakoff's syndrome are unique to this amnesic group. For instance, patients with Korsakoff's syndrome exhibit impaired temporal order judgments (Huppert \& Piercy, 1976; Squire, 1982), they fail to release from proactive interference (Cermak, Butters, \& Moreines, 1974; Squire, 1982; Winocur, Kinsbourne, \& Moscovitch, 1981), and they exhibit extensive remote memory impairment (Albert, Butters, \& Levin, 1979; Cohen \& Squire, 1981). Other kinds of amnesic patients do not always share these deficits, even though they can be as impaired or more impaired than Korsakoff patients on conventional tests of new learning ability (Cohen \& Squire, 1981; Marslen-Wilson \& Teuber, 1975; Moscovitch, 1982; Squire, 1982). These findings have suggested that patients with Korsakoff's syndrome have a broader cognitive impairment than is found in other forms of amnesia.

Accuracy of feeling of knowing was first investigated in normal subjects by Hart $(1965,1967)$. College students were asked to recall the answers to general information questions (e.g., Who painted "Afternoon at La Grand Jatte?" [Seurat]). Following the recall test, subjects predicted whether they would or would not be able to recognize the correct answer if it were presented with some likely, but incorrect choices. The feeling-ofknowing predictions were validated by a subsequent recognition test. Recognition performance was better for those questions eliciting a feeling of knowing than for those questions that did not elicit a feeling of knowing.

Versions of this procedure have been used to study feeling of knowing for different kinds of information and under various testing conditions. Studies have investigated the feeling of knowing for general information facts (Gruneberg \& Monks, 1974; Hart, 1965, 1967; Nelson, Gerler, \& Narens, 1984), for recently learned paired-associates (Hart, 1967; Nelson, Leonesio, Shimamura, Landwehr, \& Narens, 1982; Schacter, 1983), and for consonant trigrams forgotten from immediate memory (Blake, 1973). Although the accuracy of feeling-of-knowing judgments is far from perfect, the basic finding has been that these judgments reliably predict subsequent memory performance.

In the present study, we assessed accuracy of feeling of knowing in several groups of amnesic patients. We based our procedure on one developed by Nelson and his colleagues (Nelson et al., 1984; Nelson \& Narens, 1980a; Shimamura, Landwehr, \& Nelson, 1981). In Experiment 1, we assessed feeling-of-knowing accuracy for semantic knowledge presumably learned many years earlier. Amnesic patients and control subjects were asked to recall general information questions until a total of 24 incorrect responses were accumulated. Next, subjects made feelingof-knowing judgments for these 24 nonrecalled questions by producing a rank order of the questions-from the question judged most likely to be recognized to the question judged least likely to be recognized. Accuracy of these feeling-of-knowing judgments was then determined by giving a recognition test and correlating feeling-of-knowing rankings with recognition performance. In Experiment 2, we assessed feeling-of-knowing accuracy for newly learned (episodic) information. Subjects studied 24 sentences and were then asked to recall a missing word in each sentence. Following the recall test, feeling-of-knowing judgments and recognition memory was assessed in the same way as in Experiment 1. The question of interest was whether impaired feeling of knowing is an obligatory deficit of amnesia, whether it is unrelated to amnesia, or whether it occurs in only some forms of amnesia.

\section{Experiment 1 Method}

\section{Subjects}

Patients with Korsakoff's syndrome. This group consisted of 5 male and 3 female patients with alcoholic Korsakoff's syndrome. These patients averaged 54.0 years of age and had an average of 12.3 years of education. Their average full-scale Wechsler Adult Intelligence Scale (WAIS) IQ was 102.6 (range 91-114) and their average Wechsler Memory Scale (WMS) score was 78 (range 64-93). In normal subjects, the WMS score is equivalent to WAIS IQ. Neuropsychological screening and independent neurological examination indicated that memory impairment was the only notable deficit in higher cortical functions. All of these patients could draw a cube and a house in perspective and none had aphasia or apraxia. The memory impairment in this group has been documented in previous studies (Cohen \& Squire, 1981; Graf et al., 1984; Shimamura \& Squire, 1984; Squire, 1982).

Patients receiving electroconvulsive therapy (ECT). This group consisted of 4 male and 4 female patients (mean age $=46.5$ years; mean education $=15.5$ years), who were receiving a prescribed course of bilateral ECT for relief of depressive illness. ECT is known to cause anterograde and retrograde amnesia as a prominent side effect of treatment (Price, 1982; Squire, 1984). Following a postictal confusional period of about $30 \mathrm{~min}$, amnesia is present as a relatively circumscribed disorder, and it diminishes to some extent during the subsequent hours after treatment. The severity of amnesia cumulates as additional treatments of ECT are given. ECT was administered three times each week on alternate days, and testing occurred 2 to 3 hours after the third, fourth, or fifth treatment. All patients were treated with a Medcraft B-24 device, and electrode placement was bitemporal. The amnesia associated with bilateral ECT has been documented in previous studies in our laboratory (Squire, 1984; Squire et al., 1985). The WMS averages 79 at this time after ECT (Squire \& Shimamura, 1986).

Four additional cases of amnesia. Patient 1 became amnesic in 1976 following a cardiac arrest and a period of unconsciousness (age at testing $=46$; education $=20$ years; WAIS IQ $=119$; WMS $=91$ ). Patient 2 became amnesic in 1983 following a period of hypotension that occurred during major surgery (age at testing $=43$; education $=13$ years; WAIS = 104; WMS = 81). Patient 3 became amnesic in 1984 following a period of anoxia that occurred during a seizure (age at testing $=54$; education $=15$ years; WAIS-R IQ = 111; WMS = 92). The fourth patient was $\mathrm{N}$. A. This man has been severely amnesic for verbal material since 1960 when he sustained a stab wound to the brain with a miniature fencing foil (age at testing $=45$; education $=13$ years; WAIS $\mathrm{IQ}=$ 24; WMS = 97). N.A.'s memory impairment has been described elsewhere (see Kaushall, Zetin, \& Squire, 1981; Teuber, Milner, \& Vaughan, 1968). CT scans have identified a lesion in the region of the left dorsal thalamus (Squire \& Moore, 1979).

Alcoholic control subjects. We tested seven male alcoholic control subjects. These alcoholic subjects had an average drinking history of 16 years but had abstained from alcohol for an average of 9.0 weeks prior to participating in the present experiment. This group averaged 47.6 years of age, had 12.7 years of education, and had a mean WAIS subtest score of 23.7 for information (18.0 for the patients with Korsakoff's syndrome) and 51.4 for vocabulary ( 47.9 for patients with Korsakoff's syndrome). These alcoholic subjects had no history of head injury or liver disease.

\section{Materials}

A set of 100 general information questions (e.g., What is the name of the ship on which Charles Darwin made his scientific voyage? [Beagle]) 
were obtained from the pool of questions used in the FACTRETRIEVAL computer program developed by Shimamura et al. (1981). These questions were assembled by Nelson and Narens (1980b), who collected normative data for 300 questions from a sample of 270 college students. Our set of 100 questions varied in degree of difficulty from a recall probability of .97 to a recall probability of .00 . The questions tapped information about a variety of topics including geography, history, sports, literature, and entertainment. Each question was printed on a separate index card.

\section{Procedure}

Initial recall phase. Questions were presented in the same order for all subjects. The first 70 questions covered the full range of difficulty. They were presented in a mixed order. The last 30 questions in the set were all difficult items (recalled by fewer than $5 \%$ of the 270 subjects in the original normative study). Three easy practice questions were placed at the beginning of the list. The experimenter showed a question to the subject and read it aloud. Subjects were instructed that "some questions will be easy and some will be difficult-if you cannot immediately remember the answer, give yourself a chance to find it by thinking about the question a bit more." The recall phase continued until the subject missed a total of 24 questions (including errors of both omission and commission).

Feeling-of-knowing phase. Immediately following the recall phase, subjects were asked to rate each of the 24 nonrecalled questions according to their "feeling of knowing"- -that is, how likely they would be able to recognize the correct answer if given some choices. First, subjects rated each of the 24 nonrecalled questions on a 4-point scale $(1=$ high feeling of knowing; 2 = medium feeling of knowing; 3 = low feeling of knowing; 4 = pure guess). This rating procedure enabled us to assess feeling of knowing using an absolute rating technique. Subjects were told that these questions were ones that were not correctly recalled. Cue cards identifying each rating category were placed in front of the subjects to remind them of the rating scheme.

After subjects placed each of the 24 nonrecalled questions into one of the four rating categories, they then rank ordered all the questions within each category according to their feeling of knowing. To begin, subjects were given two questions from the first rating category (high feeling of knowing) and asked to determine which of the two had a stronger feeling of knowing, that is, which answer would more likely be recognized. Then, a third question from the same category was presented, and subjects ranked it in relation to the first two questions. This procedure was continued until the experimenter obtained a rank order for all questions from the first category. A rank order for questions in each of the other three rating categories was then obtained in the same way. Tied ranks were accepted, but the experimenter discouraged the subjects from producing them. On completion of the feeling-of-knowing phase, a complete rank order of the 24 nonrecalled questions had been obtained that ranged from the question that was ranked the highest in feeling of knowing to the question that was ranked the lowest.

Recognition phase. Immediately after the feeling-of-knowing phase, a seven-alternative forced-choice recognition test was given for the 24 nonrecalled questions. The alternatives came from the recognition phase of FACTRETRIEVAL (Shimamura et al., 1981). A booklet containing the questions and eight available alternatives for each question was used to assess recognition memory. If a subject gave one of the eight alternatives as an incorrect response during the initial recall phase, then that alternative was omitted from the recognition test. Otherwise, the experimenter randomly omitted one of the distractors from the recognition test. Thus, in all cases the subjects were asked to pick the correct answer from seven alternatives.

\section{Results and Discussion}

Figure 1 displays recall performance by alcoholic control subjects, patients with Korsakoff's syndrome, patients pre- scribed ECT, and four other amnesic patients. The ability to recall general information facts was different across subject groups, $F(3,22)=2.9, p<.05$. A Dunnett's test to compare each amnesic group to the alcoholic control group showed that only patients with Korsakoff's syndrome were impaired in recall, $t(22)=5.1, p<.01$. Patients with Korsakoff's syndrome recalled fewer general facts than did the four individual patients, $t(10)=2.5, p<.05$; all four patients performed well, $52 \%, 44 \%$, $60 \%, 73 \%$. The difference in recall performance between patients with Korsakoff's syndrome and patients prescribed ECT approached significance, $t(14)=1.8, p=.09$. The recall deficit exhibited by patients with Korsakoff's syndrome is consistent with the remote memory impairment known to occur in this group (Albert et al., 1979; Cohen \& Squire, 1981).

Recall performance was tested by asking subjects to recall general facts until they failed to recall 24 facts. Thus, performance was based on a different number of questions for each subject. Another way to assess recall performance is to score only those questions that were presented to all subjects. This scoring method can be adopted easily because all subjects received the questions in the same presentation order. As a result, those questions presented to the subject with the poorest recall score were presented to all subjects. The subject with the poorest recall score (an ECT patient) was presented 29 questions before making 24 incorrect responses (recall $=17.2 \%$ ). When recall performance was based on only these 29 questions - that is, the first 29 questions given to all subjects-the average recall scores for the subject groups were $64 \%, 36 \%, 53 \%$, and $64 \%$, for

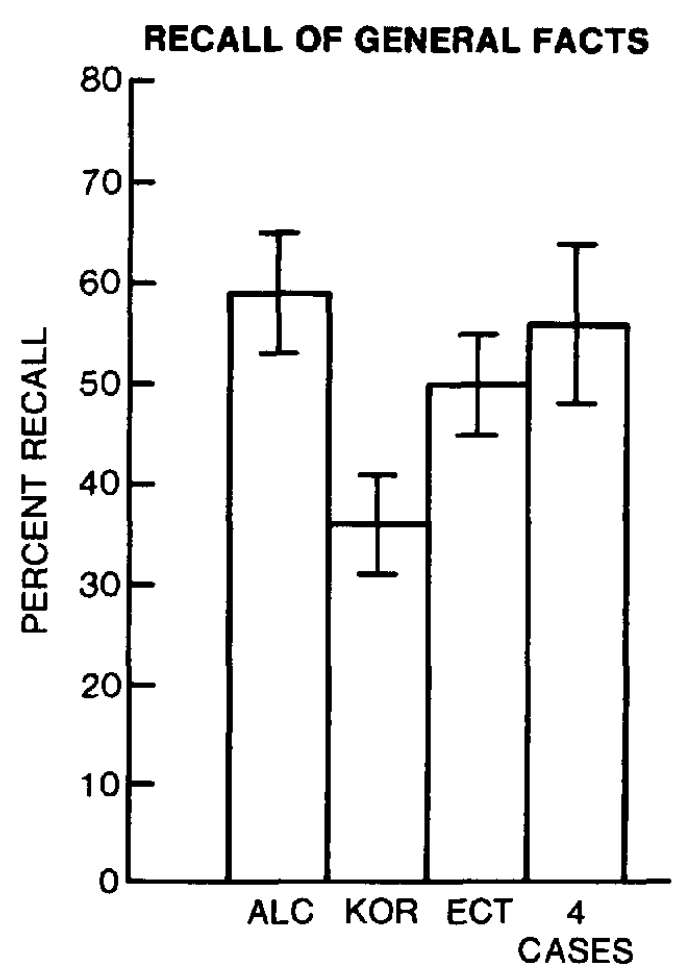

Figure 1. Recall performance for general information questions. Subjects were asked questions until they had failed 24 items (ALC $=$ alcoholic subjects; $\mathrm{KOR}=$ patients with Korsakoff's syndrome; $\mathrm{ECT}=$ patients prescribed electroconvulsive therapy; 4 cases $=$ four other amnesic patients; bars show \pm standard error of the mean.) 


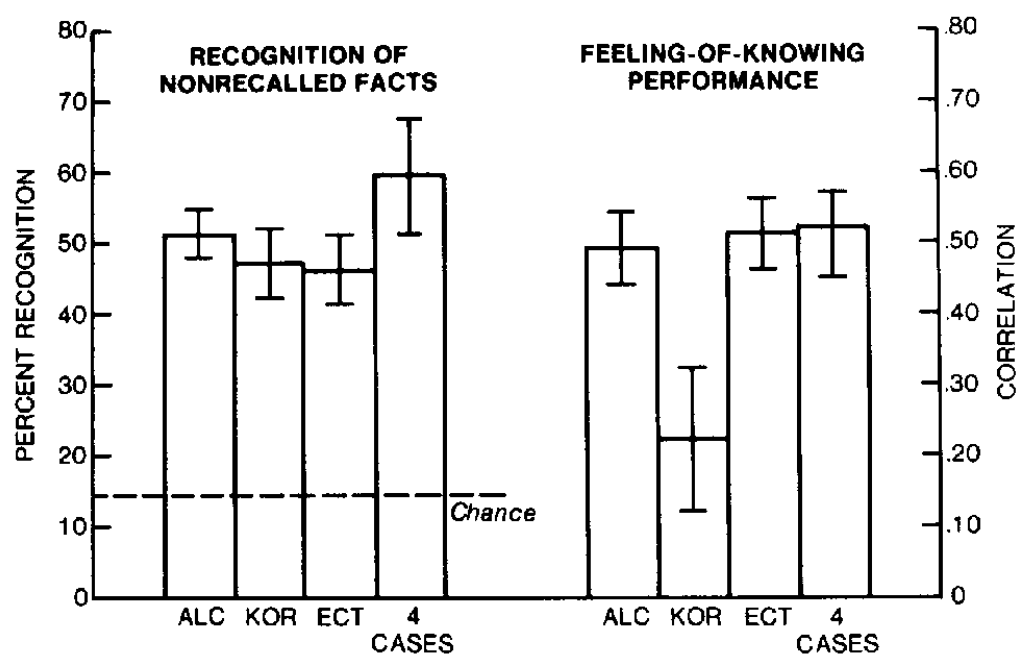

Figure 2. Recognition memory (seven-alternative, forced-choice) and feeling-of-knowing accuracy for nonrecalled facts. (Feeling-of-knowing accuracy was calculated by correlating feeling-of-knowing ranking with subsequent recognition performance. ALC = alcoholic subjects; KOR = patients with Korsakoff's syndrome; $\mathrm{ECT}=$ patients prescribed electroconvulsive therapy; 4 cases $=$ four other amnesic patients; bars show \pm standard error of the mean.)

alcoholic subjects, patients with Korsakoff's syndrome, patients prescribed ECT, and the four other amnesic patients, respectively. Thus, patients with Korsakoff's syndrome exhibited an impairment of remote memory even when recall performance was based on the same questions for all subjects.

Figure 2 shows recognition performance for 24 nonrecalled facts and feeling-of-knowing performance for these facts. There were no differences in recognition performance across subject groups, $F(3,22)=0.40, p<.05$. Previous reports have shown that patients with Korsakoff's syndrome exhibit remote memory deficits on both recall and recognition tests (Albert et al., 1979; Cohen \& Squire, 1981). The procedure used in the present study can explain why recognition performance by Korsakoff patients was better than might have been expected. Recognition performance was based on the nonrecalled facts, and patients with Korsakoff's syndrome reached the criterion of 24 nonrecalled facts earlier in the list of questions than the other subject groups. Because difficult questions were more frequent toward the end of the list, the pool of items failed by the patients with Korsakoff's syndrome was easier than the items failed by the other groups.

Recognition performance presumably would have been impaired in patients with Korsakoff's syndrome if the same questions had been given to all groups. An approximate measure of recognition performance using the same questions across groups can be obtained by assessing performance for the first 29 questions. These 29 questions were given to all subjects, though some of the questions were recalled and thus not tested for recognition. If it is assumed that an item correctly recalled will also be recognized, then recognition performance for these 29 questions was $82.7,62.3,76.0$, and 84.7 for alcoholic controls, patients with Korsakoff's syndrome, patients prescribed ECT, and the other amnesic subjects, respectively.

Figure 2 also shows feeling-of-knowing accuracy as measured by the correlation between feeling-of-knowing rankings and recognition performance. We used the Goodman-Kruskal gamma, a nonparametric correlation statistic (Hays, 1973; for its use in feeling-of-knowing research, see Nelson, 1984). Feeling-of-knowing accuracy differed across subject groups, $F(3$, $22)=4.0, p<.05$. Patients with Korsakoff's syndrome were impaired in their feeling-of-knowing accuracy compared to alcoholic controls, $t(13)=2.3, p<.05$, patients prescribed ECT $t(14)=2.6, p<.05$, and the four other amnesic patients, $t(10)=$ $2.1, p=.06$. The feeling-of-knowing scores for the four individual patients were $.63, .54, .56$, and .40 ; and the lowest score for any subject (an alcoholic subject scored .26) was still higher than the mean score for the Korsakoff group (.22). Thus, despite the fact that the patients with Korsakoff's syndrome based their feeling-of-knowing judgments on a set of questions that varied widely in difficulty, their feeling-of-knowing accuracy was impaired.

Another way to determine feeling-of-knowing accuracy is to analyze recognition performance as a function of how subjects sorted the questions into the four feeling-of-knowing categories. As shown in Table 1, all subject groups, except the patients with Korsakoff's syndrome, showed a general decrease in recognition performance across the four rating categories, from high feeling of knowing to pure guess. For instance, patients with Korsakoff's syndrome recognized $47 \%$ of the answers to the questions that they had predicted would be pure guesses, whereas the other subjects averaged only $23 \%$ correct recognition for those items rated as pure guesses (chance $=14 \%$ ). Moreover, for items rated high in feeling of knowing, patients with Korsakoff's syndrome obtained a poorer recognition score than any of the other groups. Thus, even when feeling-of-knowing judgments were based on an absolute rating techniquesimilar to that used by Hart and others (Hart, 1965, 1967; Schacter, 1983)-patients with Korsakoff's syndrome exhibited impaired feeling-of-knowing accuracy.

In summary, patients with Korsakoff's syndrome were impaired in making feeling-of-knowing judgments about their premorbid, semantic knowledge. Other amnesic patients- 
Table 1

Experiment 1: Percent Recognition Performance as a Function of Feeling-of-Knowing Category

\begin{tabular}{|c|c|c|c|c|c|c|c|c|}
\hline \multirow[b]{3}{*}{ Group } & \multicolumn{8}{|c|}{ Feeling-of-knowing category } \\
\hline & \multicolumn{2}{|c|}{ High } & \multicolumn{2}{|c|}{ Medium } & \multicolumn{2}{|c|}{ Low } & \multicolumn{2}{|c|}{ Pure guess } \\
\hline & $\%$ & $M$ & $\%$ & $M$ & $\%$ & $M$ & $\%$ & $M$ \\
\hline ALC & 67 & 8.3 & 62 & 7.4 & 39 & 4.0 & 20 & 4.3 \\
\hline KOR & 59 & 8.9 & 32 & 3.9 & 31 & 2.0 & 47 & 9.2 \\
\hline ECT & 77 & 3.2 & 77 & 4.9 & 40 & 6.9 & 22 & 9.0 \\
\hline 4 cases & 87 & 7.5 & 65 & 9.2 & 18 & 2.8 & 28 & 4.5 \\
\hline
\end{tabular}

Note. $M$ refers to the mean number of items placed in each category. ALC = alcoholic subjects; $K O R=$ patients with Korsakoff's syndrome; $\mathrm{ECT}=$ patients prescribed electroconvulsive therapy; 4 cases $=$ four other amnesic patients.

patients prescribed bilateral ECT, three patients with amnesia due to anoxia or ischemia, and subject N. A.-were as accurate as alcoholic control subjects in their feeling-of-knowing judgments. The finding that feeling-of-knowing judgments were normal in all but the Korsakoff patients indicates that impaired feeling of knowing is not an obligatory component of anterograde amnesia.

It should be noted that patients with Korsakoff's syndrome were poorer than the other groups at recalling the information about which they were asked to make feeling-of-knowing judgments. Thus, the question arises as to whether impaired feelingof-knowing performance was simply a result of this remote memory impairment. Mayes and Meudell $(1981,1984)$ showed that performance on one kind of metamemory task, that is, supplying confidence ratings for items generated on a cued recall test, is directly related to level of memory performance for both amnesic patients and control subjects. Thus, it is possible that inaccurate feeling-of-knowing judgments could result, not from impaired metamemory but from an impairment of memory itself.

This possibility seems unlikely. On a test like the one used here, feeling-of-knowing judgments should be difficult whenever the memory strengths of nonrecalled items are homogeneous. For example, if a test were very difficult for one patient group, floor effects could make the items homogeneous and thereby make feeling-of-knowing judgments difficult for that group. In the present study, the items for which patients with Korsakoff's syndrome made feeling-of-knowing judgments varied in difficulty as much as the items given to the other groups. All groups were given items covering the full range of difficulty available, as determined by the Nelson and Narens (1980b) norms. Indeed, recognition performance for nonrecalled questions was almost identical, about $50 \%$, in all subject groups. This level of performance is optimal for feeling-of-knowing studies because half the items are above the recognition threshold and half the items are below the threshold. Despite the equivalent and above-chance recognition memory scores, only patients with Korsakoff's syndrome exhibited impaired feeling of knowing.

\section{Experiment 2}

The findings of Experiment 1 demonstrated that amnesic patients can exhibit normal feeling-of-knowing accuracy. How- ever, patients with Korsakoff's syndrome did exhibit impaired feeling of knowing, and this group was the only one whose memory was impaired for the material being tested. Thus, one might suppose that amnesic patients exhibit impaired metamemory judgments, but only for the domains of memory for which they are amnesic. To explore further the relationship between amnesia and metamemory, we assessed feeling-of-knowing accuracy for newly learned information. In this experiment, all of the amnesic patients can be expected to exhibit impaired memory for the material being tested.

Subjects were presented sentences (e.g., "Patty's garden was full of marigolds") and then asked to recall a part of the sentence when presented with the remaining part (e.g., "Patty's garden was full of __"). Feeling-of-knowing judgments were made for nonrecalled information and then validated by a recognition memory test, just as in Experiment 1. We tested patients with Korsakoff's syndrome, four other amnesic patients, alcoholics, and healthy control subjects. All were tested after a 5-min retention interval. In addition, we tested groups of alcoholic and healthy control subjects after a 1-7-day retention interval in order to assess feeling-of-knowing accuracy at a time when the memory performance of control subjects was equivalent to that of the amnesic patients tested after a 5 -min retention interval. If impaired feeling-of-knowing accuracy is not an obligatory deficit of anterograde amnesia (or weak memory), then only the patients with Korsakoff's syndrome should exhibit impaired feeling of knowing.

\section{Method}

\section{Subjects}

Patients with Korsakoff's syndrome. We tested six of the eight patients described in Experiment 1; two patients were not available for testing.

Four additional cases of amnesia. See Experiment 1.

Alcoholic control subjects. This group of 19 male alcoholic control subjects had an average drinking history of 13.2 years but had abstained from alcohol for an average of 9.7 weeks prior to testing. They averaged 48.5 years of age, had 13.3 years of education, and had mean WAIS subtest scores of 17.8 for information and 43.8 for vocabulary. These alcoholic subjects had no history of head injury or liver disease. Six of these subjects were tested after a 5-min delay and the other 13 subjects were tested after a $1-7$-day delay (mean delay $=2.2$ days).

Healthy control subjects. Eighteen volunteers and employees of the San Diego Veterans Administration Medical Center were also tested. These subjects averaged 49.0 years of age and 14.6 years of education. Six of these subjects were tested after a 5-min delay and the other 12 subjects were tested after a 3-7-day delay (mean delay $=3.8$ days).

\section{Procedure}

Study phase. Twenty-four sentences were printed individually on cards and presented for study (e.g., "At the museum we saw some ancient relics made of clay"). Of the 24 sentences, 12 were presented once and the other 12 were presented twice, for a total of 36 presentations. Subjects were asked to read each sentence aloud and to study the sentences so that they could remember them later. Sentences were presented in a mixed order and were counterbalanced across presentation frequency.

Recall phase. Recall was assessed by asking subjects to recall part of a sentence when presented with the remaining part (e.g., "At the museum we saw some relics made of "). A noun was missing in each 
sentence. Subjects were encouraged to guess if they could not remember the missing word. Subjects were also told that they would be asked to add words to sentences that they had not seen previously. Eight such new sentences were included in the recall phase, and subjects thus attempted to recall or guess the missing word in each of 32 sentences ( 24 old and 8 new).

Feeling-of-knowing phase. Following the recall phase, subjects rated their feeling of knowing for all nonrecalled sentence information (including errors of both omission and commission). We used the same procedure as in Experiment 1. To summarize, subjects saw a sentence with a missing word and then rated their feeling of knowing for the missing word on a 4-point scale (high, medium, low, pure guess). Subjects also rated the eight new sentences that had been presented only in the recall phase. Subjects were told that sentences whose missing part had never been presented should be rated as pure guesses. Subjects were encouraged to use the whole range of the 4-point scale. After the nonrecalled sentences and the eight new sentences were rated, subjects rank ordered the sentences within each rating category, using the same procedure as in Experiment 1. Subjects were asked to base their feeling-ofknowing judgments on the likelihood that they could recognize the missing part if given some choices.

Recognition phase. Immediately after the feeling-of-knowing phase, subjects were given a seven-alternative, forced-choice recognition test for all 24 study sentences. As in Experiment 1, there were eight recognition choices available to the experimenter. If a subject gave one of the recognition lures as an incorrect response during the recall phase, then that choice was eliminated from the recognition test. Otherwise, the experimenter randomly eliminated one of the lures from the test.

\section{Results and Discussion}

Figure 3 displays recall performance by healthy control subjects, alcoholics, patients with Korsakoff's syndrome, four other amnesic subjects tested after a 5-min delay, and healthy control subjects and alcoholics tested after a 1-7-day delay ("delayed" subjects). There was an overall difference in recall performance across subject groups, $F(5,41)=21, p<.05, M S_{\mathrm{e}}=380$. Planned comparisons showed that healthy control and alcoholic subjects tested after a 5-min delay recalled more sentence information than amnesic patients and delayed subjects, but the amnesic patients and delayed subjects did not differ from each other $(t s<1.4)$. Also, sentences presented twice were recalled better than sentences presented once, $F(1,41)=52, p<.05$, $M S_{\mathrm{e}}=140$, and there was no interaction between presentation frequency and subject group, $F(5,41)=.63, M S_{\mathrm{e}}=140$. Specifically, for all subject groups, recall performance for sentences presented twice was raised by an average of $18.5 \%$ (range $=$ $15 \%-27 \%$ ) compared to the recall percentage of sentences presented once.

Recognition performance for the 24 study sentences (recalled and nonrecalled sentences) was significantly different across groups, $F(5,41)=11, p<.05, M S_{c}=450$. Healthy control and alcoholic subjects recognized $86 \%$ and $87 \%$ of sentences, respectively, whereas patients with Korsakoff's syndrome, the four other amnesic patients, delayed controls, and delayed alcoholic subjects recognized $46 \%, 44 \%, 53 \%$, and $53 \%$ of sentences, respectively. There was an effect of presentation frequency $F(1$, $41)=15, p<.05, M S_{\mathrm{e}}=250$, but no Subject Group $\times$ Presentation Frequency interaction, $F(5,41)=.76, M S_{\mathrm{c}}=250$.

Figure 4 shows recognition performance for the nonrecalled sentences-that is, those sentences for which subjects made feeling-of-knowing judgments. Recognition performance for

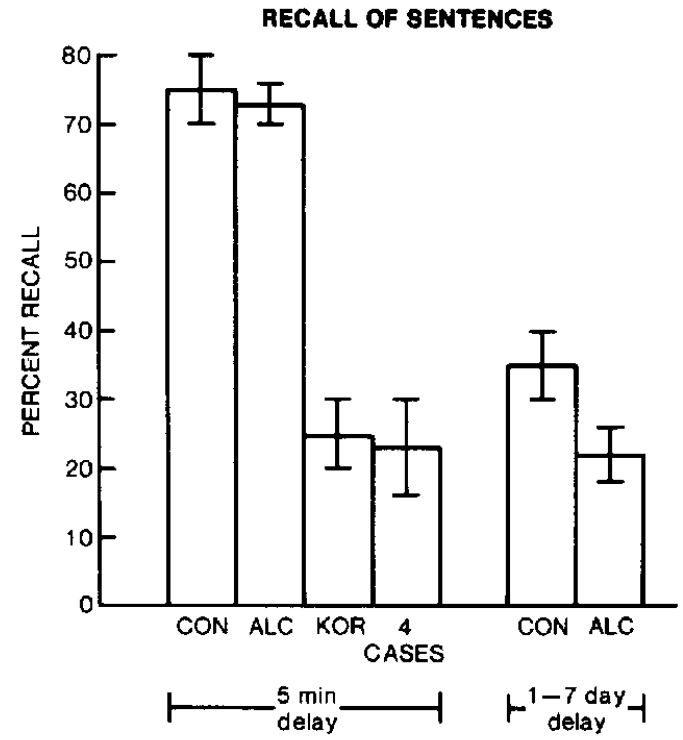

Figure 3. Performance of subjects who studied 24 sentences and were then asked to recall a missing part of each sentence. $(\mathrm{CON}=$ healthy control subjects; $\mathrm{ALC}=$ alcoholic subjects; $\mathrm{KOR}=$ patients with Korsakoff's syndrome; 4 cases $=$ four other amnesic patients; bars show \pm standard error of the mean.)

these sentences was different across subject groups, $F(5,41)=$ $3.2, p<.02, M S_{\mathrm{e}}=286$, because of the superior recognition performance of the healthy control and alcoholic subjects tested after a 5-min delay. Recognition of nonrecalled sentences for patients with Korsakoff's syndrome, the four other amnesic patients, and the delayed subjects was nearly identical (range = $35 \%-41 \%$ ).

Feeling-of-knowing performance is shown in Figure 5. As in Experiment 1, we used the Goodman-Kruskal gamma correlation between a subject's feeling-of-knowing ranking and recognition performance ( 1 or 0 score). We attempted to increase the range of memory strength by having subjects study some sentences twice, some once, and some not at all. The eight sentences that were never presented for study (but that were presented during the recall and feeling-of-knowing phases) were included in the gamma correlation and were given a 0 recognition score. This procedure increased the probability of observing above-chance feeling-of-knowing accuracy. We found differences in feeling-of-knowing accuracy across subject groups, $F(5,41)=5.9, p<.001, M S_{\mathrm{c}}=740$. Healthy control and alcoholic subjects tested after a 5-min delay exhibited exceptionally good feeling-of-knowing accuracy. This good performance can be attributed mainly to the fact that these subjects were able to discriminate those sentences that were presented for study from those sentences that were never presented for study. The four cases of amnesia and the delayed subjects performed well above chance (chance $=0$ gamma correlation). The four individual amnesic subjects scored $.52, .20, .47$, and .41 , the delayed control subjects averaged .22 , and the delayed alcoholic subjects averaged .19. Patients with Korsakoff's syndrome produced an average gamma correlation of -.007 . All subject groups except patients with Korsakoff's syndrome performed at above-chance levels. 


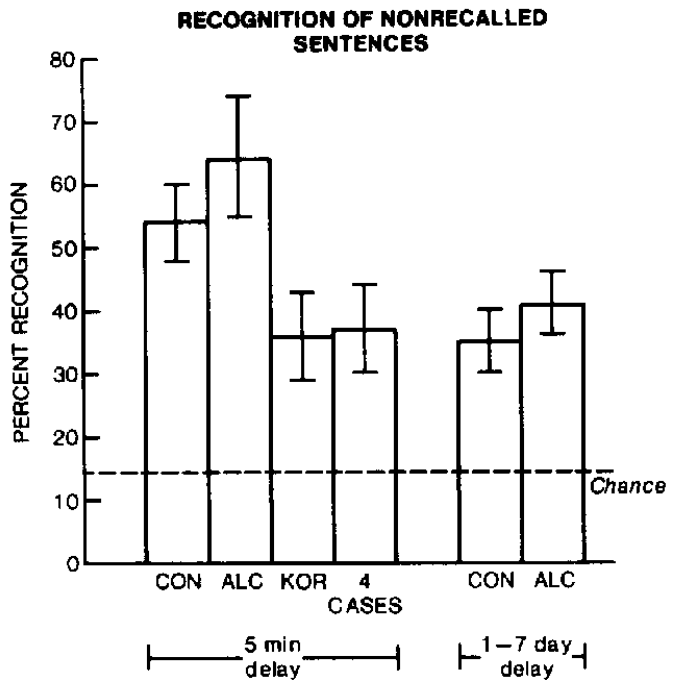

Figure 4. Recognition memory (seven-alternative, forced-choice) for nonrecalled sentence information. (CON $=$ healthy control subjects; $\mathrm{ALC}=$ alcoholic subjects; $\mathrm{KOR}=$ patients with Korsakoff's syndrome; 4 cases $=$ four other amnesic patients; bars show \pm standard error of the mean.)

Planned comparisons showed that delayed control subjects and the four amnesic patients exhibited better feeling-of-knowing accuracy than patients with Korsakoff's syndrome, $t \mathrm{~s}(13)>$ $2.2, p<.05$. The difference between the delayed alcoholic subjects and the patients with Korsakoff's syndrome approached statistical significance, $t(17)=1.82, p=.08$. Thus, despite the fact that both groups of amnesic patients and both groups of delayed subjects were matched on recognition memory for nonrecalled items, feeling-of-knowing accuracy differed among the groups. The four amnesic cases showed good feeling-of-knowing accuracy, given their level of memory performance, but the patients with Korsakoff's syndrome were impaired. Indeed, the four amnesic patients actually performed somewhat better than the two delayed groups, though these differences were marginally significant, $t \mathrm{~s}(14)<2.0, p \mathrm{~s}>.07$.

Table 2 shows recognition performance of nonrecalled sentences across the four feeling-of-knowing rating categories. Table 2 also shows the average number of nonrecalled sentences that were placed in each feeling-of-knowing category. All subject groups, except patients with Korsakoff's syndrome, showed a general decrease in recognition performance as they rated items from high feeling of knowing to pure guess. Thus, as in Experiment 1, patients with Korsakoff's syndrome exhibited impaired feeling-of-knowing judgments even when the judgments were based on an absolute rating technique.

\section{General Discussion}

Patients with Korsakoff's syndrome were impaired in making feeling-of-knowing judgments both about general information facts and about newly learned material. Specifically, patients with Korsakoff's syndrome were unable to predict whether or not the answer to a nonrecalled question would subsequently be recognized on a multiple-choice test. Feeling-of- knowing performance of other amnesic patients-patients prescribed bilateral ECT, three patients with amnesia as a result of an anoxic or ischemic episode, and patient N. A.-was as accurate as that of control subjects whose recall and recognition memory performance was matched to the performance of the amnesic patients. These findings demonstrate that memory and metamemory are not inextricably linked: Impaired feeling of knowing is not an obligatory component of anterograde amnesia.

The feeling-of-knowing impairment exhibited by patients with Korsakoff's syndrome spanned premorbid semantic memory and newly learned (episodic) memory. Because these patients were the only ones who exhibited amnesia for general semantic facts, the finding of impaired feeling of knowing in Experiment 1 could have been attributed to their memory impairment rather than to a specific impairment of metamemory. In Experiment 2, however, we assessed feeling of knowing for newly learned information, and in this case the patients with Korsakoff's syndrome were still the only ones to exhibit impaired metamemory. This occurred despite the fact that other amnesic patients studied were just as impaired in memory performance as the Korsakoff patients. In fact, the feeling-of-knowing performance of the four (non-Korsakoff) amnesic patients was somewhat above the level obtained by delayed subjects. Patients with Korsakoff's syndrome, however, performed more poorly than the delayed control subjects. Thus, Korsakoff patients appear to have a particular deficit in metamemory that cannot be explained as a result of their memory impairment. The finding that the four individual amnesic subjects performed on average somewhat above the expected level suggests that the metamemory demands for a normal subject tested after a long delay may be more difficult than the demands for an amnesic patient tested after a short delay. Despite this possible advantage in the case of some amnesic patients, pa-

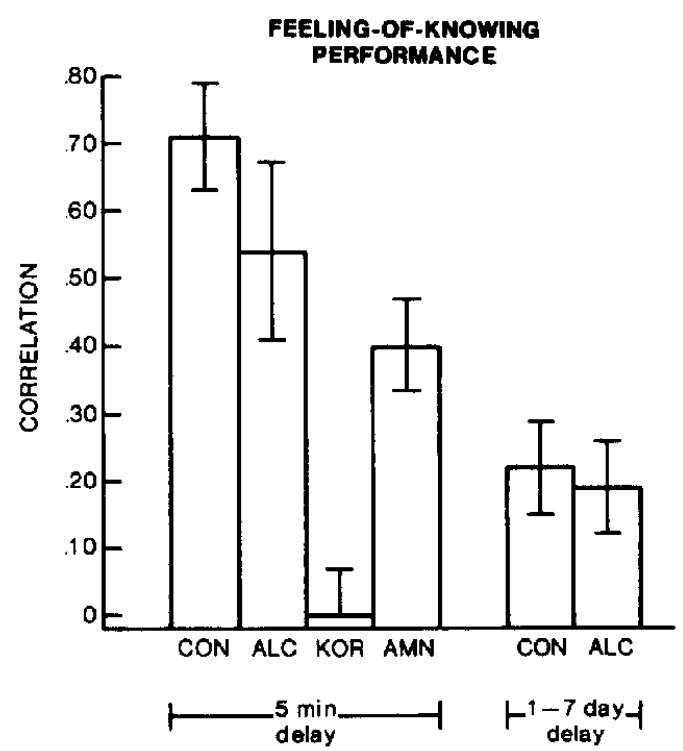

Figure 5. Feeling-of-knowing performance for each subject group. ( $\mathrm{CON}=$ healthy control subjects; $\mathrm{ALC}=$ alcoholic subjects; $\mathrm{KOR}=$ patients with Korsakoff's syndrome; 4 cases = four other amnesic patients; bars show \pm standard error of the mean.) 
Table 2

Experiment 2: Percent Recognition Performance as a Function of Feeling-of-Knowing Category

\begin{tabular}{|c|c|c|c|c|c|c|c|c|}
\hline \multirow[b]{3}{*}{ Group } & \multicolumn{8}{|c|}{ Feeling-of-knowing category } \\
\hline & \multicolumn{2}{|c|}{ High } & \multicolumn{2}{|c|}{ Medium } & \multicolumn{2}{|c|}{ Low } & \multicolumn{2}{|c|}{$\begin{array}{l}\text { Pure } \\
\text { guess }\end{array}$} \\
\hline & $\%$ & $M$ & $\%$ & $M$ & $\%$ & $M$ & $\%$ & $M$ \\
\hline CON & 69 & 2.7 & 33 & 2.5 & 30 & 1.7 & 7 & 7.5 \\
\hline ALC & 67 & 2.0 & 67 & 2.0 & 45 & 1.8 & 13 & 7.5 \\
\hline KOR & 20 & 8.3 & 18 & 7.5 & 32 & 6.7 & 45 & 7.5 \\
\hline 4 cases & 37 & 7.5 & 29 & 11.2 & 15 & 6.5 & 25 & 1.0 \\
\hline Con (delayed) & 36 & 4.6 & 22 & 6.5 & 30 & 5.3 & 14 & 6.5 \\
\hline ALC (delayed) & 35 & 6.1 & 26 & 6.7 & 28 & 6.7 & 25 & 6.7 \\
\hline
\end{tabular}

Note. $M$ refers to the mean number of items placed in each category. $\mathrm{CON}=$ control; $\mathrm{ALC}=$ alcoholic subjects; $\mathrm{KOR}=$ patients with Korsakoff's syndrome; 4 cases $=$ four other amnesic patients.

tients with Korsakoff's syndrome performed at chance on the feeling-of-knowing measure.

The finding that feeling of knowing was impaired in patients with Korsakoff's syndrome agrees with previous reports that this patient group has impaired metamemory. It was reported that these patients lack knowledge of mnemonic strategies (Hirst \& Volpe, as cited by Hirst, 1982) and that they are poor at predicting how many items will be remembered in a recall test (Bauer et al., 1984). Impaired metamemory and feeling-ofknowing accuracy adds to a growing list of impairments that appear unique to Korsakoff's syndrome (Moscovitch, 1982; Squire, 1982). Presumably, Korsakoff's syndrome typically produces a more widespread cognitive deficit than is observed in other forms of amnesia.

Although the inaccurate feeling-of-knowing judgments exhibited by patients with Korsakoff's syndrome cannot be a result of weak memory, it is possible that inaccurate feeling of knowing is linked to the impaired memory of this particular group. For example, recall, particularly of remote memories, might be influenced by the ability to make judgments about the contents of memory, perhaps because of effects on search and retrieval strategies. These strategies could affect such decisions as where to search and how long to search in memory. To the extent that recognition depends on these strategies, it too could be affected by impaired feeling of knowing. This interpretation is supported by the finding that the extensive remote memory impairment that is seen in patients with Korsakoff's syndrome is not related to their impairment in new learning capacity (Shimamura \& Squire, 1986). Alternatively, some other cognitive deficit could affect both recall and feeling-of-knowing judgments. Our findings do not address the issue of how metamemory and memory might be linked. The findings do show, however, that the impaired feeling of knowing exhibited by Korsakoff patients is a real deficit and one that cannot be explained as a result of weak memory strength.

Nelson et al. (1984) distinguished between two classes of mechanisms that may contribute to feeling-of-knowing judgments. One class involves "trace-access" mechanisms and includes processes that access specific information about to-beremembered information. A second class involves "inferential" mechanisms. Inferential mechanisms do not operate on to-beremembered information itself but are used to evaluate related and contextual knowledge so that a better assessment can be made as to the likelihood of subsequent recognition. It is not clear how to regard the impaired feeling of knowing exhibited by Korsakoff patients. These patients do have particular difficulty in remembering contextual information, such as the recency and frequency of presented material (Huppert \& Piercy, 1976; Squire, 1982). Moreover, these patients are often impaired on neuropsychological tests that require planning and judgment (Talland, 1965) and on tests sensitive to frontal lobe dysfunction (Oscar-Berman, 1980). Such cognitive deficits could affect inferential mechanisms that ordinarily contribute to accurate feeling-of-knowing judgments.

In summary, patients with severe anterograde amnesia can produce accurate feeling-of-knowing judgments. Thus, impaired feeling-of-knowing accuracy is not an obligatory feature of amnesia. Patients with Korsakoff's syndrome, however, were impaired in making feeling-of-knowing judgments for both semantic facts and newly learned (episodic) memories. This impairment in metamemory was exhibited only by patients with Korsakoff's syndrome and presumably reflects a more widespread cognitive impairment than is observed in other forms of amnesia.

\section{References}

Albert, M. S., Butters, N., \& Levin, J. (1979). Temporal gradients in the retrograde amnesia of patients with alcoholic Korsakoff's disease. Archives of Neurology, 36, 211-216.

Bauer, R. H., Kyaw, D., \& Kilbey, M. M. (1984). Metamemory of alcoholic Korsakoff patients. Society for Neuroscience Abstracts, 10, 318.

Blake, M. (1973). Prediction of recognition when recall fails: Exploring the feeling-of-knowing phenomenon. Journal of Verbal Learning and Verbal Behavior, 12, 311-319.

Brown, A. L. (1978). Knowing when, where and how to remember: A problem of metacognition. In R. Glaser (Ed.), Advances in instructional psychology (pp. 367-406). Hillsdale, NJ: Erlbaum.

Butters, N., \& Cermak, L. S. (1980). Alcoholic Korsakoff's syndrome: An information processing approach to amnesia. New York: Academic Press.

Cermak, L. S. (1982). Human memory and amnesia. Hillsdale, NJ: Erlbaum.

Cermak, L. S., Butters, N., \& Moreines, J. (1974). Some analyses of the verbal encoding deficit of alcoholic Korsakoff patients. Brain and Language, 1, 141-150.

Cohen, N. J. (1984). Preserved capacity in amnesia: Evidence for multiple memory systems. In L. Squire \& N. Butters (Eds.), Neuropsychology of memory (pp. 83-103). New York: Guilford Press.

Cohen, N. J., \& Squire, L. R. (1980). Preserved learning and retention of pattern-analyzing skill in amnesia: Dissociation of knowing how and knowing that. Science, 210, 207-210.

Cohen, N. J., \& Squire, L. R. (1981). Retrograde amnesia and remote memory impairment. Neuropsychologia, 19, 337-356.

Corkin, S. (1968). Acquisition of motor skill after bilateral medial temporal lobe excision. Neuropsychologia, 6, 225-265.

Diamond, R., \& Rozin, P. (1984). Activation of existing memories in the amnesic syndromes. Journal of Abnormal Psychology, 93, 98-105.

Flavell, J. H., \& Wellman, H. M. (1977). Metamemory. In R. V. Kail, Jr., \& J. W. Hagen (Eds.), Perspectives on the development of memory and cognition (pp. 3-33). Hillsdale, NJ: Erlbaum.

Graf, P., Squire, L. R., \& Mandler, G. (1984). The information that amnesic patients do not forget. Journal of Experimental Psychology: Learning, Memory, and Cognition, 10, 164-178. 
Gruneberg, M. M. (1983). Memory processes unique to humans. In A. Mayes (Ed.), Memory in animals and man (pp. 253-281). London: Van Nostrand.

Gruneberg, M. M., \& Monks, J. (1974). Feeling of knowing and cued recall. Acta Psychologica, 41, 257-265.

Hart, J. T. (1965). Memory and the feeling-of-knowing experience. Journal of Educational Psychology, 56, 208-216.

Hart, J. T. (1967). Memory and the memory-monitoring process. Journal of Verbal Learning and Verbal Behavior, 6, 685-691.

Hays, W. L. (1973). Statistics for the social sciences. (2nd ed.). New York: Holt, Rinehart \& Winston.

Hirst, W. (1982). The amnesic syndrome: Descriptions and explanations. Psychological Bulletin, 91, 435-460.

Huppert, F. A., \& Piercy, M. (1976). Recognition memory in amnesic patients: Effect of temporal context and familiarity of material. Cortex, 12, 3-20.

Jacoby, L. L., \& Witherspoon, D. (1982). Remembering without awareness. Canadian Journal of Psychology, 32, 300-324.

Kaushall, P. I., Zetin, M., \& Squire, L. R. (1981). A psychosocial study of chronic, circumscribed amnesia. Journal of Nervous and Mental Disease, 169, 383-389.

Marslen-Wilson, W. D., \& Teuber, H.-L. (1975). Memory for remote events in anterograde amnesia: Recognition of public figures from news photographs. Neuropsychologia, 13, 335-364.

Mayes, A. R., \& Meudell, P. R. (1981). How similar is immediate memory in amnesic patients to delayed memory in normal subject? A replication, extension and measurement of the amnesic cueing effect. Neuropsychologia, 19, 647-654.

Mayes, A. R., \& Meudell, P. R. (1984). Patterns of confidence loss in the cued recall of normal people with attenuated recognition memory: Their relevance to a similar amnesic phenomenon. Neuropsychologia, 22, 41-54.

Milner, B. (1962). Les troubles de la memoire accompagnant des lesions hippocampiques bilaterales [Memory impairment accompanying bilateral hippocampal lesions]. In Physiologie de l'hippocampe. Paris: Centre National de la Rechesche Scientifique.

Moscovitch, M. (1982). Multiple dissociations of function in amnesia. In L. Cermak (Ed.), Human memory and amnesia (pp. 337-370). Hillsdale, NJ: Erlbaum.

Nelson, T. O. (1984). A comparison of current measures of the accuracy of feeling-of-knowing predictions. Psychological Bulletin. 95, 109133.

Nelson, T. O., Gerler, D., \& Narens, L. (1984). Accuracy of feeling-ofknowing judgments for predicting perceptual identification and relearning. Journal of Experimental Psychology: General, 113, 282300.

Nelson, T. O., Leonesio, R. J., Shimamura, A. P., Landwehr, R. F., \& Narens, L. (1982). Overlearning and the feeling of knowing. Journal of Experimental Psychology: Learning, Memory, and Cognition, 8. 279-288.

Nelson, T. O., \& Narens, L. (1980a). A new technique for investigating the feeling of knowing. Acta Psychologica, 46, 69-80.

Nelson, T. O., \& Narens, L. (1980b). Norms of 300 general-information questions: Accuracy of recall, latency of recall, and feeling-of-know- ing ratings. Journal of Verbal Learning and Verbal Behavior, 19 338-368.

Oscar-Berman, M. (1980). The neuropsychological consequences of long-term chronic alcoholism. American Scientist, 68, 410-419.

Price, T. R. P. (1982). Short- and long-term cognitive effects of ECT: Part 1. Effects on memory. Psychopharmacology Bulletin, 18, 81-91.

Schacter, D. L. (1983). Feeling of knowing in episodic memory. Journal of Experimental Psychology: Learning, Memory, and Cognition, 9, 39-54.

Shimamura, A. P. (in press). Priming effects in amnesia: Evidence for a dissociable memory function. Quarterly Journal of Experimental Psychology.

Shimamura, A. P., Landwher, R. F., \& Nelson, T. O. (1981). FACTRETRIEVAL: A program for assessing someone's recall of general-information facts, feeling-of-knowing judgments for nonrecalled facts, and recognition of nonrecalled facts. Behavior Research Methods \& Instrumentation, 13, 691-692.

Shimamura, A. P., \& Squire, L. R. (1984). Paired-associate leaming and priming effects in amnesia: A neuropsychological study. Journal of Experimental Psychology: General, 113, 556-570.

Shimamura, A. P., \& Squire, L. R. (1986). Korsakoff's syndrome: A study of the relation between anterograde amnesia and remote memory impairment. Behavioral Neuroscience, 100, 165-170.

Squire, L. R. (1982). Comparisons between forms of amnesia: Some deficits are unique to Korsakoff's syndrome. Journal of Experimental Psychology: Learning, Memory, and Cognition, 6, 560-571.

Squire, L. R. (1984). ECT and memory dysfunction. In B. Lerer, R. D., Weiner, \& R. H. Belmaker (Eds.), ECT: Basic mechanisms (pp. 156162). London: John Libbey.

Squire, L. R., \& Cohen, N. J. (1984). Human memory and amnesia. In G. Lynch, J. L. McGaugh, \& N. M. Weinberger (Eds.), Neurobiology of learning and memory (pp. 3-64). New York: Guilford Press.

Squire, L. R., \& Moore, R. Y. (1979). Dorsal thalamic lesion in a noted case of chronic memory dysfunction. Annals of Neurology, 6, 503506.

Squire, L. R., \& Shimamura, A. P. (1986). Characterizing amnesic patients for neurobehavioral study. Manuscript submitted for publication.

Squire, L. R., Shimamura, A., \& Graf, P. (1985). Independence of recognition memory and priming effects: A neuropsychological analysis. Journal of Experimental Psychology: Learning. Memory and Cognition, 11, 37-44.

Talland, G. A. (1965). Deranged memory: New York: Academic Press.

Teuber, H.-L., Milner, B., \& Vaughan, H. G. (1968). Persistent anterograde amnesia after stab wound of the basal brain. Neuropsychologia, $6,267-282$.

Weiskrantz, L. (1982). Comparative aspects of studies of amnesia. In D. E. Broadbent \& L. Weiskrantz (Eds.), Philosophical Transactions of the Royal Society of London (Vol. 298, pp. 97-109). London: The Royal Society.

Winocur, G., Kinsbourne, M., \& Moscovitch, M. (1981). The effect of cuing on release from proactive interference in Korsakoff amnesic patients. Journal of Experimental Psychology: Human Learning and Memory, 7, 56-65.

Received December 3, 1984 Revision received October 21, 1985 